\title{
COMPLEMENTARY HALFSPACES AND TRIGONOMETRIC CEVA-BROCARD INEQUALITIES FOR POLYGONS
}

\author{
ADI BEN-ISRAEL AND STEPHAN FOLDES
}

\begin{abstract}
The product of ratios that equals 1 in Ceva's Theorem is analyzed in the case of non-concurrent Cevians, for triangles as well as arbitrary convex polygons. A general lemma on complementary systems of inequalities is proved, and used to classify the possible cases of non-concurrent Cevians. In the concurrent case, particular consideration is given to the Brocard configuration defined by equal angles between Cevians and polygon sides.
\end{abstract}

Mathematics subject classification (1991): 51M16, 51M20, 51M04, 51M15.

Key words and phrases: Triangle geometry, Brocard angle, Brocard points, Ceva theorem, convex polygons, half-spaces, inequalities.

\section{REFERENCES}

[1] Exercise 100 \& Solution (C. B. Seymour), Ann. of Math. 2 (1886), 119-120; 3 (1887), 55-62.

[2] F. ABI-KhUZAM, Proof of Yff's Conjecture on the Brocard Angle of a Triangle, Elem. Math. 29 (1974), $141-142$.

[3] A. Beutelspacher and U. Rosenbaum, Projective Geometry: from foundations to applications, Cambridge University Press 1998.

[4] A. L. CRELLE, Über einige Eigenschaften des ebenen geradlinigen Dreiecks rücksichtlich dreier durch die Winkelspitzen gezogenen geraden Linien, Berlin, 1816.

[5] P. DAVIS, The Rise, Fall and Possible Transfiguration of Triangle Geometry: A Mini-History, Amer. Math. Monthly 102 (1995), 204-214.

[6] B. Grünbaum and G. C. Shephard, Ceva, Menelaus and the Area Principle, Math. Mag. 68 (1995), 254-268.

[7] B. GrünBaum and G. C. ShePhard, A New Ceva-Type Theorem, Math. Gazette 80 (1996), 492-500.

[8] B. GrÜNBAUM AND G. C. SHEPHARD, Ceva, Menelaus and Selftransversality, Geom. Dedicata 65 (1997), 179-192.

[9] B. GRÜNBAum AND G. C. SHEPHARD, Some New Transversality Properties, Geom. Dedicata 71 (1998), 179-208.

[10] L. Guggenbuhl, Henri Brocard and the Geometry of the Triangle, Math. Gazette 32 (1953), 241-243.

[11] J. P. HogENDIJK, Mathematics in Medieval Islamic Spain, Proc. Intl. Congress of Mathematicians Zurich 1994, Birkhäuser Verlag, Basel, (1995), 1568-1580.

[12] R. Honsberger, Episodes in Nineteenth and Twentieth Century Euclidean Geometry, Math. Assoc. Amer., 1995.

[13] R. A. Johnson, Modern Geometry: An Elementary Treatise on the Geometry of the Triangle and the Circle, Houghton Mifflin, Boston, 1929.

[14] C. Kimberling, Triangle Centers as Functions, Rocky Mountain J. Math. 23 (1993), 1269-1286.

[15] C. Kimberling, Central Points and Central Lines in the Plane of a Triangle, Math. Mag. 67 (1994), $163-187$.

[16] C. KimBerling, A Class of Major Centers of Triangles, Aequationes Math. 55 (1998), 251-258.

[17] C. Kimberling, Triangle Centers and Central Triangles, Congressus Numerantium 1291998.

[18] D. S. Mitrinović, J. E. PeČARIĆ And V. VoleneC, Recent Advances in Geometric Inequalities, Kluwer Academic Publishers, Dordrecht/Boston/London, 1989.

[19] L. S. SHIVELY, An Introduction to Modern Geometry, J. Wiley \& Sons, New York, 1939. 
[20] R. J. Stroeker, An Inequality for Yff's Analogue of the Brocard Angle of a Plane Triangle, Nieuw Archief voor Wiskunde (4th series) 4 (1986), 33-45.

[21] R. J. Stroeker, Brocard Points, Circulant Matrices and Descartes' Folium, Math. Mag. 61 (1988), $172-187$.

[22] R. J. Stroeker and H. J. T. Hoogland, Brocardian Geometry Revisited, or Some Remarkable Inequalities, Nieuw Archief voor Wiskunde (4th series) 2 (1984), 281-310.

[23] E. W. WeIssteIn, CRC Concise Encyclopedia of Mathematics, CRC Press, Boca Raton, 1998.

[24] P. YFF, An Analogue of the Brocard Points, Amer. Math. Monthly 70 (1963), 495-501. 